\title{
Therapeutic Effect and Mechanism of Action of Low-molecular-weight Whey Protein Capable of Activating Macrophages in Bovine Mastitis
}

\author{
TORU TASAKA ${ }^{1,2}$, KATSUHIKO MAEHASHI $^{3}$, HISATSUGU YAMADA ${ }^{1}$, AKIHIRO SHIRAI $^{1}$, HIDEKI UNUMA $^{2}$, \\ KEN TOKUNAGA ${ }^{2}$, AKIO HAYAKAWA ${ }^{2}$, AKITERU GO ${ }^{2}$, KIKYO GO ${ }^{4}$ and YOSHIHIRO UTO ${ }^{1}$ \\ ${ }^{1}$ Institute of Technology, Industrial and Social Sciences, Tokushima University Graduate School, Tokushima, Japan; \\ ${ }^{2}$ Kohkan Pharmaceutical Institute Co., Ltd., Tokyo, Japan; \\ ${ }^{3}$ NOSAI Tokushima, Tokushima, Japan; \\ ${ }^{4}$ Dermatology Go Clinic, Tokyo, Japan
}

\begin{abstract}
Background/Aim: Bovine mastitis is caused by the invasion and propagation of pathogenic microorganisms into the udder and mammary gland tissues of cattle. In this study, the therapeutic effect of a low-molecular-weight whey protein (LMW-WP) on bovine mastitis was evaluated. Materials and Methods: $L M W-W P$ was orally, intraperitoneally, and vaginally administered to bovine with mastitis. The number of somatic cells in milk was measured $24 h$ before the administration of LMW-WP. The effect of LMW-WP on cytokine production was measured with a microarray that evaluates the expression of cytokines. Results: In the group that received 1,000 mg intraperitoneally, the somatic cell count was reduced to less than 400,000 at the shipment standard value in three of the four udders, indicating $75 \%$ efficacy. The group that received 1,000 mg by vaginal administration showed $67 \%$ efficacy. It was confirmed that LMW-WP increased the production of cytokines such as $I L-5, I L-6, I L-9, I L-12, M C P$ 1 , and VEGF in mouse macrophage cells, but it did not show any antibacterial activity. Conclusion: LMW-WP may be an effective therapeutic agent for bovine mastitis.
\end{abstract}

Bovine mastitis is a general term used to describe the inflammation caused by the invasion of pathogenic

This article is freely accessible online.

Correspondence to: Dr. Yoshihiro Uto, Institute of Technology, Industrial and Social Sciences, Tokushima University Graduate School, Tokushima University, 2-1 Minamijosanjima-cho, Tokushima, 770-8506, Japan. Tel/Fax: +81 886567514, e-mail: uto.yoshihiro@tokushima-u.ac.jp

Key Words: Low-molecular-weight whey protein, bovine mastitis, macrophages, cytokines. microorganisms such as bacteria into the udder and mammary gland tissues of cattle. Many abnormalities can appear in the milk as a result, including the degeneration of milk quality, a decrease in the yield, an increase in the number of somatic cells, and an abnormal $\mathrm{pH}$. These can be accompanied by breast swelling, pain, hotness, and redness. As a result, cows affected by mastitis may have reduced milk production and quality and may require expenditure on treatment. Additional drawbacks may arise, such as wasted milk due to shipping restrictions, the renewal of culling, penalties on milk prices due to an increased somatic cell count, and loss of work. The impact of bovine mastitis on dairy management is significant; economic losses are approximately 80 billion yen in Japan each year $(1,2)$. Over 140 known pathogenic microorganisms cause mastitis, and their diversity makes treatment difficult (3). Currently, antibiotics are the primary treatment modality for mastitis. However, there are concerns about the use of antibiotics in cattle, such as waste milk that has been disposed due to shipping restrictions, the complexity of drug selection, and the emergence of drug-resistant bacteria due to the chronic overuse of antibiotics (4). Various alternatives to antibiotics such as ozone therapy, oral administration of stevia, and intramammary recombinant bovine granulocyte macrophagecolony stimulating factor (rbGM-CSF) have been studied, but no effective treatment has been established thus far (5-7).

Previously, a low-molecular-weight whey protein (LMWWP) that has been suggested to have a high absorption; functionality has been developed successfully through hydrolysis of a whey protein with immunopotentiating and immunomodulating properties $(8,9)$. LMW-WP has been reported to induce macrophage phagocytosis and the production of tumor necrosis factor (TNF)- $\alpha$ (10). TNF- $\alpha$ exerts a variety of physiological and pathogenic effects on the activation of a cascade of inflammatory cytokines and tissue dysfunction and destruction (11). Additionally, high 
concentrations of LMW-WP have been reported to induce production of IL-10, an anti-inflammatory cytokine (10). Therefore, the ability of LMW-WP to activate phagocytosis by macrophages and to produce cytokines was hypothesized to be effective against mastitis caused by various bacterial infections. In addition, whey peptides possess antibacterial properties and contain lactoferrin $(12,13)$, which is involved in host defense mechanisms against various infectious diseases and cancers. In this study, LMW-WP was administered to bovines with mastitis, and changes were evaluated regarding the somatic cell count in milk and comprehensive cytokine production. This study attempted to elucidate the mechanism of action of LMW-WP in bovine mastitis.

\section{Materials and Methods}

Preparation of LMW-WP. $50 \mathrm{~g}$ of whey protein (PRODIET 80S; Ingredia, France) was dissolved in $500 \mathrm{ml}$ of $100 \mathrm{mM}$ sodium phosphate buffer (SPB) $(\mathrm{pH}=7.0)$ and stirred for approximately 20 min to yield a $10 \%$ whey protein solution. A protease (Proteax; AMANO Enzyme Inc., Nagoya, Japan) with $5 \%$ whey protein by weight in the mixed solution was added, and the solution was reacted at $50^{\circ} \mathrm{C}$ for $1 \mathrm{~h}$, and then at $80^{\circ} \mathrm{C}$ for $5 \mathrm{~min}$ to inactivate the enzyme.

Clinical trial of mastitis using $L M W-W P$. The number of somatic cells in milk was measured $24 \mathrm{~h}$ before the administration of LMWWP. The International Federation of Dairy defines mastitis as having a somatic cell count of $400,000 / \mathrm{ml}$ or more, and this standard is used in Japan (14). Bovine udders with a somatic cell count of $400,000 / \mathrm{ml}$ or more were used as mastitis specimens. The route of an LMW-WP administration was either oral, intraperitoneal, or vaginal. In the oral administration group, three cows (seven udders) were used as samples, and one cow (one udder) was used as the control. A single dose of LMW-WP (100 g) dissolved in water was administered, and the number of somatic cells was measured immediately before administration, as well as $6 \mathrm{~h}, 12 \mathrm{~h}, 24 \mathrm{~h}$, and $5 \mathrm{~d}$ after administration. The specimens were collected by removing dirt from the nipples during milking, disinfecting the nipples with isopropanol, and collecting the milk by hand-squeezing five times. The measurement of somatic cells was performed by the Tokushima Dairy Agriculture Association. Five days later, the udders for which the number of somatic cells was less than $400,000 / \mathrm{ml}$ were judged to be effective. In the intraperitoneal administration group, three cows (five udders) were treated with a dose of $300 \mathrm{mg}$, two cows (four udders) were treated with $1000 \mathrm{mg}$, and one cow (three udders) was used as the control. LMW-WP (300 mg or $1000 \mathrm{mg}$ ) dissolved in physiological saline was continuously injected intraperitoneally for five days, and the number of somatic cells was counted on days one through six. The udders whose somatic cell counts became less than $400,000 / \mathrm{ml}$ at the end of the six-day period were considered to be effective. In the vaginal administration group, four cows (nine udders) were used as samples, and one cow (three udders) was used as the control. The capsule-filled LMW-WP (1000 $\mathrm{mg}$ ) was continuously injected into the vagina for five days, and the criteria were the same as those in the intraperitoneal administration group. Cows for clinical trials were provided by three farms in the Tokushima Prefecture.
Evaluation of cytokine production ability. RAW 264.7 cells (KAC Co., Ltd., Kyoto, Japan) were cultured in Dulbecco's modified Eagle medium (DMEM) (Wako, Osaka, Japan) for $48 \mathrm{~h}$, and then washed with $1 \mathrm{X}$ phosphate-buffered saline (PBS). A serum-free DMEM, $10 \mathrm{mg}$ of whey protein, or $10 \mathrm{mg}$ of LMW-WP was added, and the mixture was incubated at $37^{\circ} \mathrm{C}$ for $48 \mathrm{~h}$, followed by supernatant collection. The microarray used was a Quantibody ${ }^{\circledR}$ Mouse Cytokine Array (RayBiotech Life Inc., Norcross, GA, USA). After being washed, the array was scanned using an array scanner GenePix ${ }^{\circledR}$ 4400A (Molecular Devices LLC, Sunnyvale, CA, USA). Using the analysis software Array-Pro Analyzer ${ }^{\circledR}$ Ver.4.5 (Media Cybernetics, Inc., Rockville, MD, USA) the fluorescence intensity value at each spot was calculated from the obtained image (TIFF image, 16-bit format). Microarray measurements and analyses were performed at Filgen, Inc. (Aichi, Japan).

Minimal inhibitory concentration (MIC) measurement by microliquid dilution method. Whey protein $(200 \mathrm{mg}$ ) and LMW-WP were dissolved in $1 \mathrm{ml}$ of distilled water and sterilized with a 0.2 $\mu \mathrm{m}$ syringe filter. The whey protein solution and the LMW-WP solution were diluted with Nutrient broth medium (NB medium) to prepare a concentration of 98 to $50,000 \mu \mathrm{g} / \mathrm{ml}$. The diluted solutions were added to a 96 -well microplate in $80 \mu \mathrm{l}$ portions. A coagulasepositive staphylococcal strain (S. aureus subsp. aureus NBRC 12732) that had been cultured at $37^{\circ} \mathrm{C}$ for $16 \mathrm{~h}$ was added to each well at a concentration of $1 \times 10^{6}$ cells/well. To serve as a blank, 160 $\mu \mathrm{l}$ of the NB medium alone was added to one well. For the control, a mixture of $80 \mu \mathrm{l}$ of the NB medium and coagulase-positive staphylococci $\left(1 \times 10^{6}\right.$ cells $)$ was prepared. The microplate was incubated at $37^{\circ} \mathrm{C}$ for $24 \mathrm{~h}$. As a criterion, the concentration at which no bacterial growth was observed after the incubation period was defined as the MIC value.

Statistical analysis. Data have been expressed as the mean \pm standard deviation of at least three independent experiments. The statistical significance of the differences between the results was analyzed using the Student's $t$-test. A $p<0.05$ was considered statistically significant.

\section{Results}

Therapeutic effect of LMW-WP on bovine mastitis. In the oral administration group, efficacy of LMW-WP was confirmed five days after administration in one of the seven udders. (Figure 1A). In the $300 \mathrm{mg}$-intraperitoneal group, efficacy was not confirmed in any of the udders, but in the $1000 \mathrm{mg}$-intraperitoneal group, efficacy was confirmed in three out of the four udders $(75 \%)$ (Figure 1B, C). In the vaginal-administration group, efficacy was confirmed in six out of the nine udders (67\%) (Figure 1D). In addition, the somatic cell count tended to decrease in all udders of the $1000 \mathrm{mg}$-intraperitoneal and vaginal-administration groups on day six after administration of LMW-WP, compared with the somatic cell counts before administration. These results confirm that an intraperitoneal or a vaginal administration of $1000 \mathrm{mg}$ of LMW-WP effectively reduces symptoms of bovine mastitis and may be considered as a viable treatment option. 

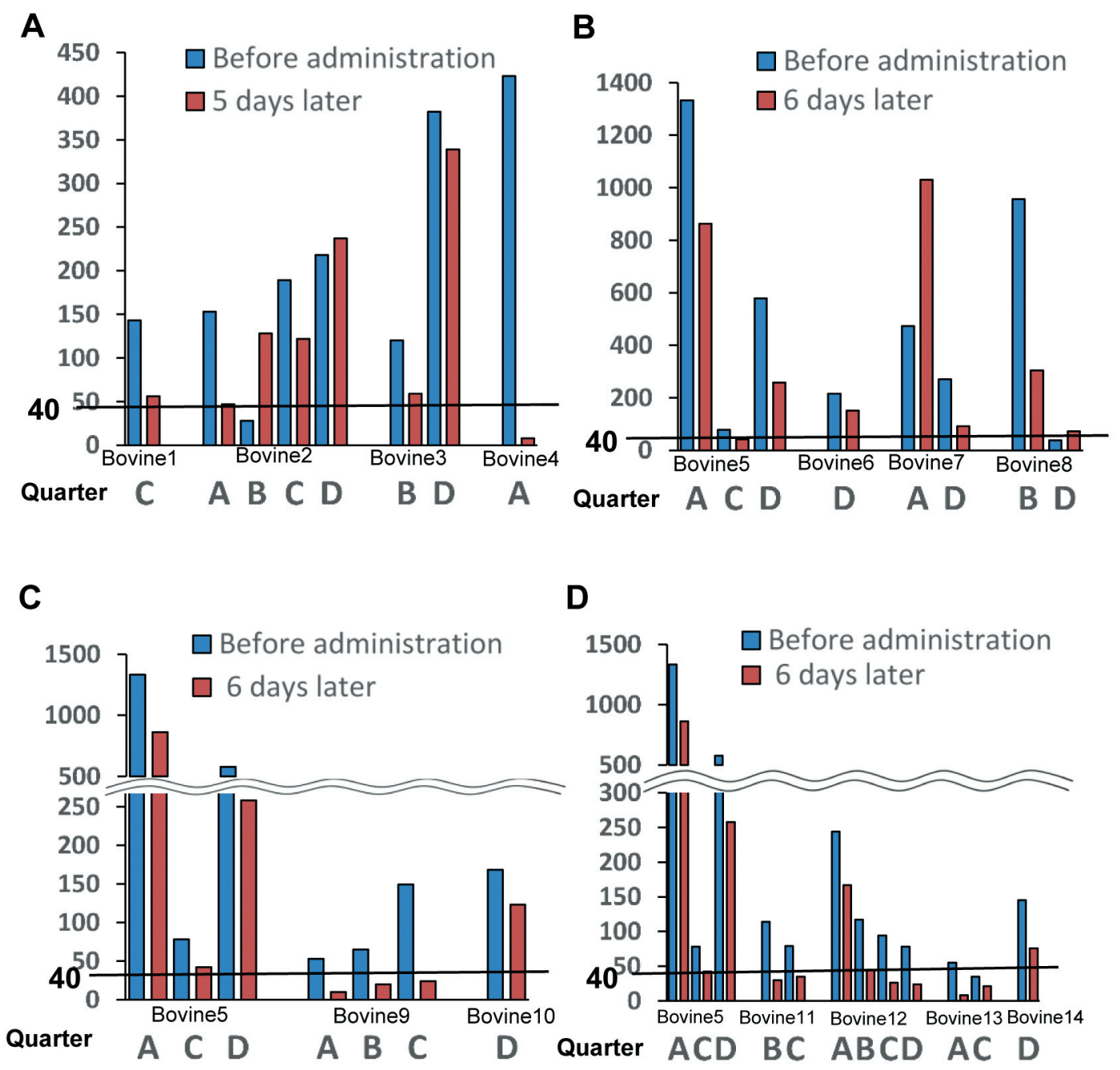

Figure 1. Number of somatic cells in milk in each udder before and after administration of the LMW-WP. (A) Oral administration group and (B) 300 mg-intraperitoneal administration group and (C) 1000 mg-intraperitoneal administration group and (D) vaginal-administration group. The udders A to D represent the positions of the udders. (A: front left, B: left back, C: front right, D: right back).

Comprehensive analysis of the cytokine production ability of $L M W-W P$. The cytokine production ability of LMW-WP was measured with a microarray to evaluate the expression of cytokines other than TNF- $\alpha$ and IL-10, which have been previously studied (10). The results showed that LMW-WP, in comparison with whey protein, increased the production of the following cytokines: IL-5 (1.53 times), IL-6 (1.77 times), IL-9 (1.49 times), IL-12 (1.45 times), MCP-1 (15.03 times), and VEGF (2.06 times) (Figure 2).

Antibacterial activity of $L M W-W P$. One potential mechanism of action of LMW-WP against bovine mastitis is as follows: LMW-WP may contain an antimicrobial peptide, and the action of the antimicrobial peptide may reduce the bactericidal effect of the causative bacteria. However, the inhibitory effect of the bacteria could not be confirmed up to the maximum concentration of $50,000 \mu \mathrm{g} / \mathrm{ml}$ (Table I). This result indicated that antimicrobial peptides were not present in the LMW-WP.

\section{Discussion}

In this clinical trial for bovine mastitis, the first oral route of LMW-WP administration was simple and did not require the assistance of a veterinarian, but efficacy was confirmed in only one udder (14\%). One reason for the failure of this treatment method to reduce the number of somatic cells in milk is the fact that the digestive system of bovine ruminants is more complex than that of other organisms. Bovines have four stomachs; the largest of these is called the rumen (lumen), which has a 

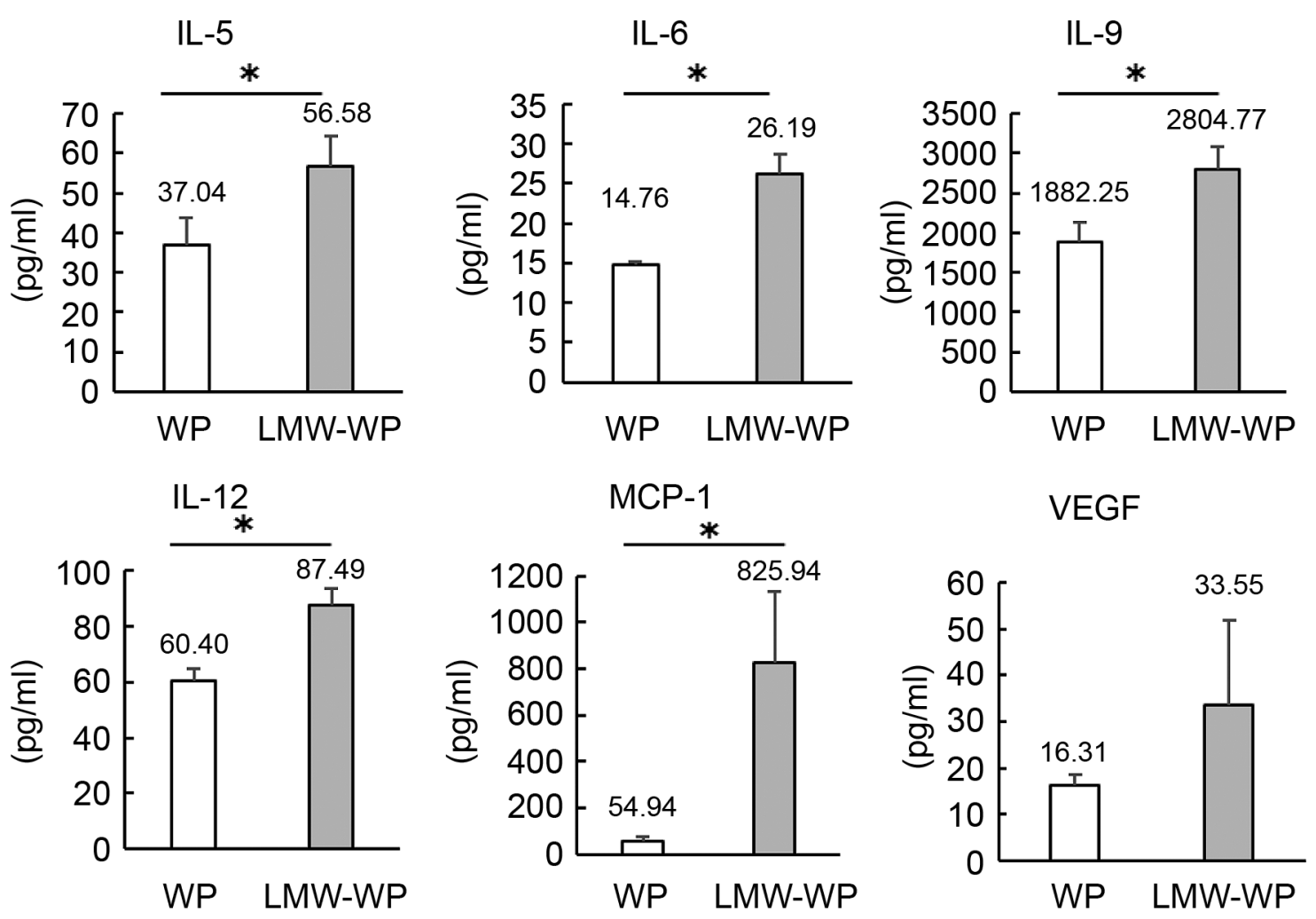

Figure 2. Cytokine production by macrophages stimulated with whey protein and LMW-WP. Data have been presented as mean $\pm S D(* p<0.05)$.

Table I. Antibacterial activity of LMW-WP.

\begin{tabular}{|c|c|c|c|c|c|c|c|c|c|c|c|c|}
\hline & \multirow{2}{*}{$\begin{array}{l}\text { Fungal } \\
\text { species }\end{array}$} & \multicolumn{11}{|c|}{ Sample concentration $(\mu \mathrm{g} / \mathrm{ml})$} \\
\hline & & 50,000 & 25,000 & 12,500 & 6250 & 3125 & 1563 & 781 & 391 & 195 & 98 & 0 \\
\hline WP & S.A. & + & + & + & + & + & + & + & + & + & + & \\
\hline LMW-WP & S.A. & + & + & + & + & + & + & + & + & + & + & \\
\hline Control & S.A. & & & & & & & & & & & + \\
\hline Blank & & & & & & & & & & & & - \\
\hline
\end{tabular}

S.A.: Staphylococcus aureus; Control: mixed solution of the NB medium and bacterial solution; blank: NB medium only. +: Growth of the test bacteria was observed. -: No growth of the test bacteria was observed.

capacity of 180 liters in the adult cattle (15). Many microorganisms coexist in the rumen, and by the action of these microorganisms, feed such as grass is fermented and converted into a nutritionally useful form. Therefore, it is likely that LMW-WP, the active ingredient, was degraded by microorganisms coexisting in the rumen before it could exert any therapeutic effects. In order to improve the bioavailability of LMW-WP, administration was performed intraperitoneally. As a result, no effect was obtained at $300 \mathrm{mg}$, but the therapeutic effect was confirmed at $1000 \mathrm{mg}$, suggesting that the dosage of LMW-WP that is effective for mastitis may be $1000 \mathrm{mg}$ or more. However, an intraperitoneal administration has to be performed by a veterinarian, which presents a challenge for administering this treatment to animals on farms. Therefore, an intravaginal administration was examined as a method that can be administered by non-veterinary doctors and deliver a high bioavailability. In the intravaginal group, a $67 \%$ therapeutic effect was observed after $1000 \mathrm{mg}$ was administered continuously for five days. This result suggests that LMW-WP is absorbed by the mucous membrane in the vagina. 
Next, in order to elucidate the mechanism of action of LMW-WP on bovine mastitis, the cytokine production ability of LMW-WP was evaluated. Enhanced production of the following cytokines was confirmed: IL-5 (16), which selectively promotes the proliferation and differentiation of eosinophils, prolongs survival, and promotes the migration of inflammation-related molecules; IL-6 (17), which is involved in immune responses, hematopoiesis, acute phase response, and B cell differentiation and IL-12 (18), which suppresses the growth of bacteria at the initial stage of infection by activating macrophages. In particular, MCP-1, the monocyte chemotactic factor, showed an approximate 15fold increase in the production ability. MCP-1 is extensively involved in the enhancement of the phagocytic activity of macrophages, which suggests that one of the mechanisms of action of LMW-WP is suppression of bacterial growth via an activation of the immune system.

Activation of macrophages by LMW-WP has been hypothesized to induce two types of macrophage differentiation. First, it induces differentiation into the M1-type macrophages at the site of infection in the udder tissue and exhibits an antibacterial activity against pathogenic bacteria. Next, since the LMW-WP's ability to produce VEGF was confirmed, the induction of differentiation into the M2-type macrophages with anti-inflammatory and immunosuppressive functions terminated the tissue damage reaction and repaired the tissue (19). These are two probable reasons why the LMWWP was able to decrease the number of somatic cells in milk.

Another possible mechanism of action of the LMW-WP on bovine mastitis under consideration involved the antimicrobial peptides contained in the LMW-WP. However, the results of the antimicrobial test showed that the antimicrobial peptides were not involved.

In conclusion, LMW-WP may be an effective therapeutic agent for bovine mastitis because LMW-WP exhibits a growth inhibitory effect on Staphylococcus aureus and Streptococcus, the causative bacteria of bovine mastitis, by inducing the phagocytic activity of macrophages and production of various cytokines. In the future, the application of LMW-WP may prove to be an effective treatment modality for various cancers and infectious diseases.

\section{Conflicts of Interest}

The Authors declare no conflicts of interest regarding this study.

\section{Authors' Contributions}

T.T. and Y.U.designed the study. T.T, K.M., H.Y., and A.S. carried out all experiments and drafted the manuscript. H.U., K.T., A.H., A.G., K.G., and K.G gave technical support and conceptual advice. As the principal investigator, Y.U. supervised the study. All Authors read and approved the final manuscript.

\section{References}

1 Tsenkova R, Atanassova S, Kawano S, and Toyoda K: Somatic cell count determination in cow's milk by near-infrared spectroscopy: A new diagnostic tool. J Anim Sci 79: 2550-2557, 2001. PMID: 11721833. DOI: $10.2527 / 2001.79102550 x$

2 Takahashi H: Early diagnosis and cytokine therapy of subclinical mastitis in dairy cows. Proceedings of Japanese Society for Animal Nutrition and Metabolism 49: 59-70, 2005. Available at: https://agriknowledge.affrc.go.jp/RN/2010720283 (in Japanese)

$3 \mathrm{Kiku} Y$ : The questionnaire on diagnosis, treatment and prevention of bovine mastitis in Japan. Journal of Japanese Society for Clinical Infectious Disease in Farm Animals 5: 6374, 2010. Available at: www.kachikukansen.org/kaiho/PDF/5-263.pdf (in Japanese)

4 Henriques $\mathrm{M}$ and Gomes F: Control of bovine mastitis: Old and recent therapeutic approaches. Current Microbiol 72: 377-382, 2016. PMID: 26687332. DOI: 10.1007/s00284-015-0958-8

5 Enginler SÖ, Sabuncu A, Kahraman BB, Koçak Ö, Yıldar E and Güzel Ö: Comparison of intramammary ozone administration doses in dairy cows with clinical mastitis. Acta Sci Vet 43: 1-7, 2015.

6 Ikuta K, Yamaguchi E, Hakogi E, Takagi M and Chida Y: Effects of the oral use of fermented stevia (stevia rebaudiana) extract on chronic or subclinical mastitis of dairy cows. Bulletin of the Hyogo Prefectural Technology Center for Agriculture, Forestry and Fisheries 43: 10-15, 2007.

7 Ozawa T, Kiku Y, Mizuno M, Inumaru S, Kushibiki S, Shingu $\mathrm{H}$, Matsubara $\mathrm{T}$, Takahashi $\mathrm{H}$ and Hayashi $\mathrm{T}$ : Effect of intramammary infusion of rbGM-CSF on SCC and expression of polymorphonuclear neutrophil adhesion molecules in subclinical mastitis cows. Vet Res Commun 36: 21-27, 2012. PMID: 22057639. DOI: 10.1007/s11259-011-9506-6

8 Marshall K: Therapeutic applications of whey protein. Alter Med Rev 9: 136-156, 2004. PMID: 15253675.

9 Rusu D, Drouin R, Pouliot Y, Gauthier S and Poubelle PE: A bovine whey protein extract stimulates human neutrophils to generate bioactive IL-1Ra through a NF-kappaB- and MAPKdependent mechanism. J Nutr 140: 382-391, 2010. PMID: 20032479. DOI: $10.3945 /$ jn.109.109645

10 Tasaka T, Kuwada E, Izuchi Y, Nishigawa R, Yamada H, Unuma $\mathrm{H}$, Tokunaga K, Hayakawa A, Go A, Go K and Uto Y: Concentration-dependent activation of inflammatory/antiinflammatory functions of macrophages by hydrolyzed whey protein. Anticancer Res 38: 4299-4304, 2018. PMID: 29970565. DOI: 10.21873 /anticanres.12728

11 Yang MD, Hsu CM, Chang WS, Yueh TC, Lai YL, Chuang CL, Wang SC, Jeng LB, Ji HX, Hsiao CL, Wu CN, Tsai CW, Chung JG and Bau DT: Tumor necrosis factor- $\alpha$ genotypes are associated with hepatocellular carcinoma risk in taiwanese males, smokers and alcohol drinkers. Anticancer Res 35: 54175424, 2015. PMID: 26408704.

12 Sugawara G, Yokoyama Y, Ebata T, Igami T, Mizuno T and Nagino M: Prevention of perioperative infectious complications in patients undergoing hepatectomy for biliary cancer. JJBA 32 : 849-859, 2018. DOI: 10.11210/tando.32.849

13 Li D, Sakashita S, Morishita Y, Kano J, Shiba A, Sato T and Noguchi M: Binding of lactoferrin to IGBP1 triggers apoptosis in a lung adenocarcinoma cell line. Anticancer Res 31: 529-534, 2011. PMID: 21378334. 
14 Arai I: Historical review of the quality control of raw milk in Japan. Milk Sci 55: 201-215, 2007. DOI: 10.11465/milk.55.201

15 Obara Y: "Applications of Stable Isotopes in Life Sciences". Utilization of stable isotopes in nutritional physiology of domestic ruminant. Radioisotopes 56: 393-401, 2007. DOI: 10.3769/radioisotopes.56.393

16 Takatsu K: Allergic inflammation and eosinophils: Trials, tribulations and enigma of IL-5, eosinophils and asthma. Arerugy 54: 48-52, 2005. PMID: 15864017.

17 Hashizume M and Ohsugi Y: IL-6 as a target in autoimmune disease and inflammation. Nihon Yakurigaku Zasshi 144: 172177, 2014. PMID: 25312286. DOI: 10.1254/fpj.144.172
18 Kawamura I: Protective immunity against mycobacterium tuberculosis. Kekkaku 85: 539-546, 2010. PMID: 17154048.

19 Tomioka H, Tatano Y, Sano C and Shimizu T: M1 and M2 macrophage populations: those induced and activated by mycobacterial infections. Kekkaku 91: 75-82, 2016. PMID: 27263230 .

Received May 23, 2020

Revised June 15, 2020

Accepted June 22, 2020 